\section{Acesso a vacinas no Brasil no contexto da dinâmica global do Complexo Econômico-Industrial da Saúde}

\author{
Access to vaccines in Brazil and the global \\ dynamics of the Health Economic-Industrial \\ Complex
}

\author{
Acceso a vacunas en Brasil en el contexto de \\ la dinámica global del Complejo Económico- \\ Industrial de la Salud
}

\author{
Carlos Augusto Grabois Gadelha 1 \\ Patricia Seixas da Costa Braga 1 \\ Karla Bernardo Mattoso Montenegro 1 \\ Bernardo Bahia Cesário 1
}

doi: $10.1590 / 0102-311 \times 00154519$

\section{Resumo}

Este estudo investigou as principais tendências econômicas, da estrutura de mercado, e da produção e inovação em vacinas contra doenças infecciosas, em âmbito global e nacional, observando os reflexos no acesso à vacinação no Brasil e sustentabilidade do Sistema Único de Saúde. Para atualização do panorama mundial de PED e de mercado, foi realizada uma pesquisa bibliográfica, e, utilizada a base de dados de inteligência competitiva. Para a compreensão da inserção do Brasil nesse contexto, segundo enfoque estrutural do Complexo Econômico-Industrial da Saúde, foram levantadas informações da Agência Nacional de Vigilância Sanitária, do Programa Nacional de Imunização e da base Questel Orbit Intelligence, referentes à proteção patentária no país; identificadas as tecnologias transferidas para as instituições públicas nacionais; e investigada a evolução do déficit da balança comercial em saúde. A análise efetuada evidenciou a tendência global de concentração da produção em poucas empresas farmacêuticas líderes e de acirramento de assimetrias econômicas e tecnológicas também no segmento de vacinas. No Brasil, a pesquisa identificou fragilidades tecnológicas, riscos e gargalos produtivos que recaem sobre a garantia à imunização no país e revelou que, a despeito da base industrial instalada, as políticas públicas e ações dos produtores nacionais não têm sido suficientes para enfrentar e superar o contexto global de dependência estrutural. Em conclusão, o estudo indica a necessidade de se avançar na estratégia nacional de vincular produção local, capacitação tecnológica e de inovação no segmento de vacinas para contribuir na garantia do acesso universal à saúde no país.

Política Nacional de Ciência, Tecnologia e Inovação; Vacinas; Programas de Imunização; Inovação; Acesso a Medicamentos Essenciais e Tecnologias em Saúde

\author{
Correspondência \\ C. A. G. Gadelha \\ Fundação Oswaldo Cruz. \\ Av. Brasil 4036, sala 809, Rio de Janeiro, RJ 21045-360, Brasil. \\ carlos.gadelha@fiocruz.br \\ 1 Fundação Oswaldo Cruz, Rio de Janeiro, Brasil.
}




\section{Introdução}

O desenvolvimento de vacinas e o estabelecimento de estratégias globais de imunização contra enfermidades altamente infecciosas foram decisivas para a alteração radical no padrão das doenças que afetam a humanidade. Evidências apontam que, nos últimos 50 anos, a vacinação foi responsável por salvar mais vidas no mundo do que qualquer outro produto ou procedimento médico, o que tornaria as vacinas, nas palavras de Roy Anderson, "o milagre da medicina moderna" 1. Reconhecida como uma das mais efetivas intervenções de saúde pública no mundo 2, a despeito dos recentes movimentos de certos segmentos da sociedade em contrário, a vacinação é consagrada como um componente essencial do direito à saúde, uma responsabilidade individual, comunitária, social e governamental 3.

$\mathrm{O}$ acesso à vacinação, entretanto, é condicionado por aspectos econômicos, uma vez que a sua indústria integra o subsistema de base química e biotecnológica do Complexo Econômico-Industrial da Saúde (CEIS) 4,5 e segue o padrão competitivo desse setor. Inserido em um sistema produtivo de elevada complexidade e dinamismo tecnológico, o mercado de vacinas se caracteriza como um oligopólio diferenciado baseado na ciência, cuja indústria enfrentou um forte processo de concentração nas últimas décadas. $\mathrm{O}$ crescente domínio das empresas líderes farmacêuticas globais nesse segmento 6,7 vem elevando o custo para a aquisição de vacinas, especialmente as de última geração, e impondo limites capazes de comprometer e mesmo inviabilizar o acesso para populações, países e regiões mais vulneráveis, acirrando iniquidades.

Considerando que aspectos inerentes ao processo de inovação e globalização se impõem como elementos centrais para se pensar as estratégias nacionais no segmento de vacinas, o presente trabalho investigou as principais tendências econômicas da estrutura de mercado e de produção em âmbito global, bem como observou a inserção do Brasil nesse contexto. O enfoque adotado é sistêmico e visa analisar a dinâmica recente associada ao desenvolvimento, à produção e ao fornecimento de vacinas no mundo, identificando seus reflexos e os desafios impostos ao acesso universal à saúde no país.

\section{Metodologia}

O foco incontornável na inovação - conforme perspectiva seminal Schumpeteriana 8,9 e neoschumpeteriana 10,11 de que a mudança tecnológica em seu sentido amplo constitui o principal fator endógeno das estratégias competitivas empresariais (não advém de fatos aleatórios ou de um conhecimento externo casual) - é essencial para pensar a dinâmica econômica, compreender as assimetrias globais, identificar os riscos e oportunidades para países menos desenvolvidos e suas instituições, assim como para apontar as ameaças à sustentabilidade dos sistemas de saúde.

Para atualização do panorama mundial de pesquisa e desenvolvimento (P\&D) de vacinas, foi realizada uma pesquisa bibliográfica, e foram utilizados dados secundários extraídos da base de inteligência competitiva Cortellis, da Clarivate Analytics (https://clarivate.com/cortellis/, acessado em 15/Abr/2019). Na base acessada, em razão dos desafios inerentes à complexidade tecnológica desse segmento, atrelado a longos prazos de desenvolvimento e alta taxa de insucesso, o recorte metodológico realizado limitou o campo de busca aos estudos clínicos em andamento de vacinas indicadas para doenças infecciosas. Não foram considerados produtos já registrados ou lançados no mercado, pois o interesse foi apontar um cenário de futuro, de curto e médio prazo, para a introdução de inovações no mercado. A partir desse levantamento, foram investigados quais são as principais doenças alvo, quais são os países líderes e quem são os principais detentores das patentes associadas a essas tecnologias.

Passando do cenário do mercado global para o nacional, foram consultadas fontes de dados secundárias da Câmara de Regulação do Mercado de Medicamentos (CMED), instância regulatória vinculada à Agência Nacional de Vigilância Sanitária (Anvisa) 12,13,14, por compilar a totalidade dos dados das aquisições realizadas para o mercado privado e parte daquelas destinadas ao mercado público; e primárias do Programa Nacional de Imunização (PNI) (que reúne informações referentes ao mercado público de vacinas), tendo sido levantadas todas as aquisições de vacinas realizadas pelo Ministério da Saúde nos últimos dez anos. As informações da CMED e do PNI são complementares e indispensáveis para a compreensão do mercado nacional de vacinas humanas. 
Adicionalmente, considerando que as patentes são reconhecidas, a despeito de limitações e críticas, como um indicador de inovação 15 capaz de associar estratégias comerciais dos investidores em P\&D, foi realizado um estudo sobre o panorama da proteção patentária nesse segmento no Brasil. Para esse fim, utilizou-se de dados de famílias de patentes indexadas na base de patentes Questel Orbit Intelligence (https://www.questel.com/business-intelligence-software/orbit-intelligence/\#, acessado em 23/Jun/2019). Foram executadas buscas sucessivas, utilizando o modo Pesquisa Avançada, sem restrição temporal, com as palavras-chave "vaccin" ou "antigen", combinadas com operadores booleanos e truncagem; associadas à Classificação Internacional de Patentes (IPC, sigla em inglês) A61K39/00 ("Preparações medicinais contendo antígenos ou anticorpos") aplicada ao título, reivindicações e resumo dos documentos de patentes. Foi obtida uma amostra inicial de 2.776 famílias de patentes vigentes no Brasil (dentre patentes depositadas e concedidas), e, para maior precisão da amostra, foi realizada uma classificação individualizada dos dados - que considerou vacinas tanto para profilaxia quanto terapêuticas, sendo excluídos documentos relacionados a vacinas destinadas exclusivamente para área veterinária, métodos de vacinação, materiais e dispositivos relacionados a vacinas -, reduzindo a amostra para 1.475 documentos. Essa investigação revelou quais são as organizações líderes no ranking de patenteamento no país; qual tipo de aplicação os principais depositantes estão concentrando seus investimentos, esforços em pesquisa e estratégias comerciais.

Com a finalidade de compreender as estratégias de transferência de tecnologia adotadas pelos laboratórios públicos nacionais, foram consultados documentos oficiais e releases dessas instituições visando identificar especialmente quais tecnologias estão sendo absorvidas e quais os principais parceiros.

Finalmente, com base na tradição estruturalista 16 e na moderna teoria da complexidade 17 - que preconizam a balança comercial como principal indicador da especialização produtiva e das assimetrias globais entre países, empresas e regiões, contemplando uma tradição no estudo do CEIS e de seus desdobramentos para a política pública 18 -, o estudo se debruçou sobre aspectos do déficit da balança comercial brasileira referente ao setor de vacinas. Utilizou-se de informações disponíveis na base de dados Comex Stat do Ministério da Indústria, Comércio Exterior e Serviços (http://comexstat. mdic.gov.br/pt/geral, acessado em Fev/2019), com coleta e sistematização realizadas a partir de metodologia desenvolvida pela Coordenação das Ações de Prospecção e pelo Grupo de Pesquisa sobre Desenvolvimento, Complexo Econômico-Industrial e Inovação em Saúde (GIS), Escola Nacional de Saúde Pública Sergio Arouca/Presidência da Fundação Oswaldo Cruz (Fiocruz). Como resultado, foram identificadas a participação das vacinas e as oscilações dessa participação no déficit comercial do CEIS, apontando para fragilidades e riscos que ainda recaem sobre a garantia de acesso à imunização no país e a conformação do sistema universal de saúde brasileiro.

O trabalho realizado contemplou o levantamento e a análise de dados e informações de mercado global e nacional de vacinas, da dinâmica empresarial e de inovação, assim como a investigação de aspectos reveladores de assimetrias e de dependência. Não demandou estudos com seres humanos, não exigindo submissão a comitês de ética, além do que, não foi identificado conflito de interesses.

\section{Resultados e discussão}

\section{Mercado global de vacinas: pesquisa, desenvolvimento e inovação}

A origem moderna do desenvolvimento de vacinas remonta ao trabalho de Edward Jenner, ainda no fim do século XVIII. De lá para cá, muito se avançou em termos de complexidade tecnológica. De vacinas simples produzidas com vírus atenuados evoluímos a vacinas multivalentes que utilizam cepas antigênicas do patógeno em circulação, a exemplo da pneumonia e do papilomavírus humano (HPV) ${ }^{1}$. Na era da indústria 4.0, começam a ser desenvolvidas vacinas a partir de mosaicos genéticos, construídos segundo modelos conceituais que utilizam grande variedade de genes sequenciados e acumulados em bases de dados globais 19 .

Inicialmente, universidades, institutos de pesquisa e laboratórios públicos - isoladamente ou em parceira com a iniciativa privada - eram protagonistas no desenvolvimento de vacinas, mas, ao longo do tempo, a importância da participação da iniciativa privada foi ampliada 20. Hoje, a atividade de 
P\&D nesse segmento é permeada pela acentuada articulação entre os setores público e privado. O Estado assume o risco nas fases mais básicas e incertas da inovação, e a indústria, nas etapas mais avançadas do desenvolvimento e na posterior introdução de novos produtos e processos no mercado 21. Nesse cenário, passa a prevalecer a predominância da lógica financeira do capital, com uma clara hegemonia das empresas líderes no padrão de inovação em termos da busca de novos produtos e na direção das atividades de P\&D, gerando assimetrias entre regiões, países e populações 18,22,23. Investidores que articulam fundos públicos e privados nas diversas formas de capital de risco, bancos públicos e órgãos de fomento internacionais também participam desse processo.

A mudança na dinâmica de desenvolvimento de vacinas pode ser associada a fatores diversos. Além da própria consolidação e do crescimento da indústria farmacêutica, o elevado valor agregado de vacinas tecnologicamente mais avançadas - algumas com vendas anuais superiores a um bilhão de dólares -, a expansão desse mercado - especialmente em razão de políticas de vacinação universal promovidas pela Organização Mundial da Saúde (OMS), a partir do fim dos anos de 1970 - e a queda de produtividade de novos medicamentos verificada nos anos 2000 contribuíram para a ampliação do interesse da indústria em investir nesse segmento 3,24,25.

Hoje, a lógica de mercado dos grandes conglomerados farmacêuticos, cuja estratégia concorrencial restringe o acesso a novas tecnologias, passou a permear a dinâmica do segmento de vacinas, elevando o preço de produtos tecnologicamente mais avançados 7 . Poucos grupos econômicos, quase exclusivamente de matriz norte-americana e europeia, são apontados como os responsáveis por praticamente quase a totalidade de vacinas desenvolvidas - revelando as assimetrias globais manifestas no processo de inovação na saúde 26,27. Uma investigação na base de dados Cortellis (https:// clarivate.com/cortellis/, acessado em 15/Abr/2019) sobre os testes clínicos em andamento contra doenças infecciosas no mundo revela que o desenvolvimento de produtos para a imunização contra enfermidades que afligem de forma desproporcional populações menos favorecidas continua não sendo prioridade. Na amostra investigada, foram identificados 374 estudos, e, se considerarmos a profilaxia, apenas vacinas contra a tuberculose (infecção por Mycobacterium tuberculosis) e malária (infecção por Plasmodium falciparum) possuem destaque no rol das 15 vacinas com maior número de testes em andamento (Figura 1), evidenciando a lógica de concentração dos esforços tecnológicos para o atendimento de demandas de populações com maior nível de renda.

Esses estudos - conduzidos especialmente nos Estados Unidos, seguidos de China e Europa (principalmente no Reino Unido, Espanha, Alemanha, Finlândia e Bélgica) - estão associados a patentes cuja titularidade é atribuída a um diversificado universo de empresas, universidades, instituições científicas e organismos governamentais - com destaque para a GlaxoSmithKline (GSK), o Governo dos Estados Unidos, a Merck, a Janssen, a Sanofi Pasteur e a Novartis. Adicionalmente, pesquisas apontam que, nos últimos cinco anos, ocorreu uma diminuição do ritmo de crescimento do pipeline de vacinas da grande indústria 26,28, com um aumento da participação de players de mercados emergentes e por pequenas empresas de biotecnologia 26.

Há que se ter cautela nessa análise, uma vez que o investimento em startups e outros empreendimentos de risco, sem perda do controle sobre o ritmo e a direção das inovações, é uma estratégia típica de concentração industrial do mercado farmacêutico, em que assimetrias de poder se reproduzem na dinâmica de inovação no segmento de vacinas, conformando um padrão de dependência centro-periferia e caracterizando um processo de modernização com marginalização que se traduz em limitações de acesso à saúde que não se restringem ao custo proibitivo de produtos de última geração, mas que são igualmente associadas a um padrão de tecnologias que não atende necessariamente as prioridades das populações menos favorecidas 16,29 .

\section{Mercado global de vacinas: dinâmica recente da produção e fornecimento}

Em 2018, o mercado farmacêutico mundial apresentou um faturamento de USD 864 bilhões, sendo USD 30,5 bilhões referentes à venda de vacinas, 3,5\% da receita do setor. Esse segmento manteve a quinta colocação no mercado, ficando atrás apenas dos oncológicos (14,3\%), antirreumáticos (6,7\%), antidiabéticos (5,6\%) e antivirais (4,5\%) 30. Dados de mercado revelam que o segmento de vacinas, nas últimas décadas, apresentou uma taxa de crescimento duas vezes maior do que a do resto da indústria farmacêutica 26. Apesar desse ritmo ter desacelerado nos últimos anos, a expectativa é de que a ten- 
Figura 1

Vacinas contra doenças infecciosas. Testes clínicos em andamento no mundo.

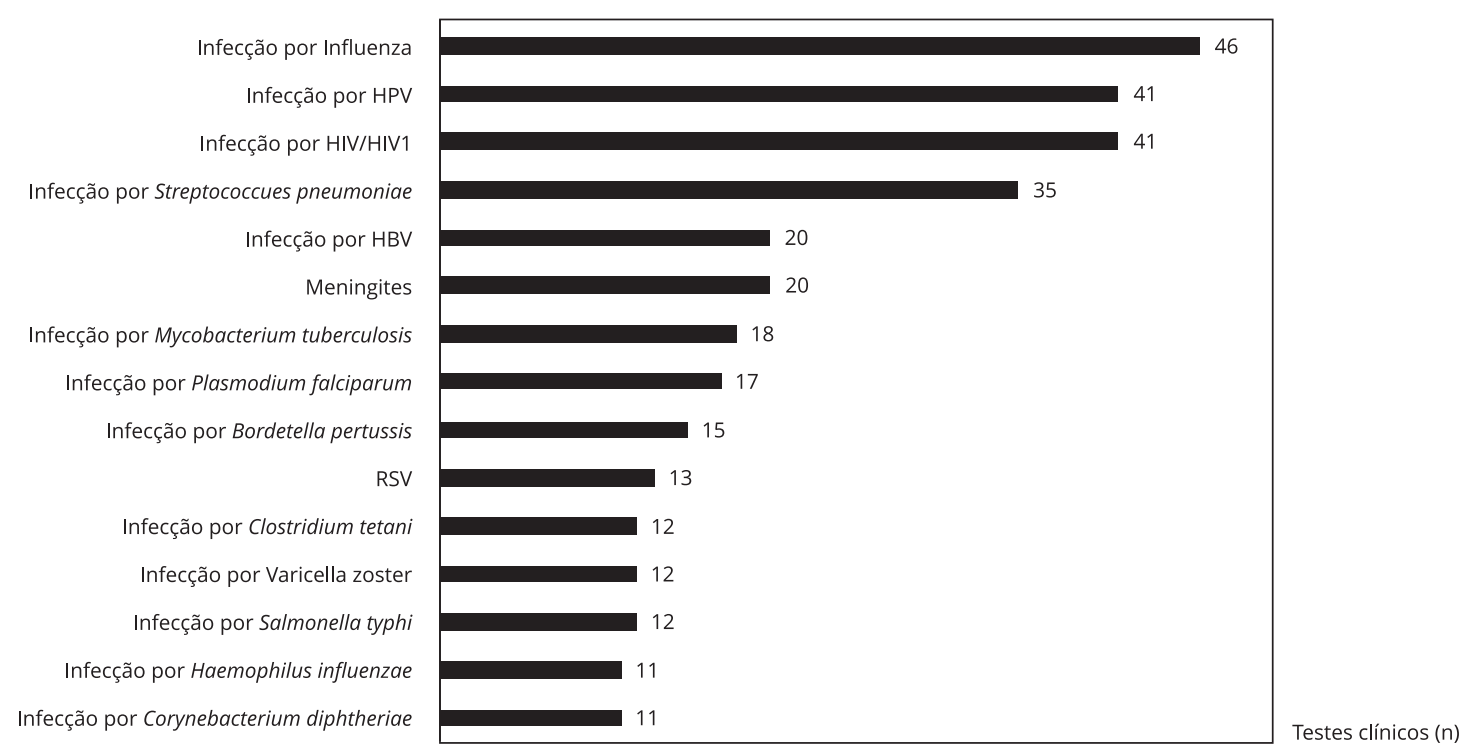

HBV: vírus da hepatite B; HIV: vírus da imunodeficiência humana; HPV: papilomavírus humano; RSV: vírus sincicial respiratório. Fonte: elaborado pelos autores com base em dados do Cortellis (https://clarivate.com/cortellis/, acessado em 15/Abr/2019).

dência de crescimento será mantida - projeções indicam um faturamento de quase USD 37 bilhões em 2027 -, o que deverá resultar na ampliação da parcela desse segmento no mercado global do setor farmacêutico 31,32.

Essas previsões consideram aspectos como o ainda elevado percentual de mortes por doenças evitáveis por vacinas já disponíveis no mercado e pelas vacinas que estão no pipeline ${ }^{33}$, devendo ser considerado também que o desenvolvimento de vacinas terapêuticas - que, diferentemente das vacinas tradicionais, destinadas à prevenção de doenças, possuem o objetivo de controlar infecções crônicas ou doenças degenerativas já instaladas, como aquelas indicadas para melhorar a resposta imunológica contra o vírus da imunodeficiência humana (HIV) e efeitos da hepatite B - terá um impacto ainda maior no mercado futuro 26.

Se observado o ano de 2017, apenas quatro grupos econômicos - GSK (24\%), Merck (23\%), Pfizer (22\%) e Sanofi (21\%) - foram os responsáveis por aproximadamente $90 \%$ do total do valor auferido com as vendas de vacinas no mundo 31 .

Nesse mercado, países de alta renda, mais propensos e em condições de implementar vacinas inovadoras e mais caras, representam $82 \%$ das receitas globais de vendas, mas correspondem a apenas cerca de $20 \%$ do volume anual das doses de vacinas fornecidas 34 . Em países de baixa e média renda, o fornecimento é parcialmente operado por organismos internacionais como o Fundo das Nações Unidas para a Infância (UNICEF) e a Organização Pan-Americana da Saúde (OPAS), que, por adquirirem grandes volumes de vacina, possuem considerável influência e conseguem preços mais baixos do que muitos países conseguiriam individualmente. Nessas regiões, fabricantes de países emergentes, estabelecidos especialmente a partir de 1980, cujo portfólio é composto, em particular, por vacinas subutilizadas básicas e algumas combinadas, desempenham papel crítico no abastecimento. A participação desses fabricantes é apontada como responsável pelo aumento da concorrência e consequente redução de preços nesses mercados, levando grandes corporações a terceirizar a produção, a participar de atividades de desenvolvimento conjunto e a realizar transferências tecnológicas, a exemplo do ocorrido no Brasil nos últimos 20 anos, como estratégia de competitividade 35. 
Apesar da ampliação do número de produtores de vacinas, ainda são poucos os capazes de atender aos padrões internacionais de qualidade estabelecidos pela OMS, levando a um tênue equilíbrio entre demanda e oferta em muitos mercados e comprometendo a imunização da população mundial 20,36.

\section{O mercado brasileiro de vacinas}

Segundo dados da CMED referentes a 2017, o mercado farmacêutico brasileiro movimentou aproximadamente BRL 69,5 bilhões, tendo apresentado um crescimento nominal de 9,4\% em relação ao ano de $2016^{12}$, o que representa um total descolamento com a forte crise econômica brasileira. O segmento de vacinas foi responsável por BRL 3,8 bilhões dessa receita (5,4\% do total), sendo que duas vacinas aparecem no ranking dos cinco maiores faturamentos do setor no país: a pneumocócica 10-valente (conjugada), em 3o lugar; e a influenza trivalente (fragmentada, inativada), em 5o lugar - cada uma com receitas superiores a BRL 500 milhões 12 .

Esses números, todavia, não incluem a totalidade de aquisições de vacinas realizadas pelo PNI, mais de BRL 3,6 bilhões no mesmo ano - possivelmente por uma subnotificação dos produtores públicos, considerada a especificidade da administração orçamentária no âmbito dos estados e da União (inclusão das receitas como recursos orçamentários, por exemplo) e por não serem computadas informações como as relacionadas aos fornecimentos realizados via OPAS - o que torna a participação das vacinas no mercado farmacêutico nacional ainda maior do que o revelado pela CMED.

Esses dados conjugados evidenciam a importância econômica das vacinas humanas no Brasil, cujo mercado se divide em dois segmentos: um público, espaço onde a população tem acesso aos produtos definidos como essenciais pelo Estado, sendo o Ministério da Saúde responsável pela aquisição e distribuição das vacinas que são ofertadas na rede pública pelo Sistema Único de Saúde (SUS); e, outro privado, organizado em torno de clínicas, consultórios e outros espaços particulares 37 .

O mercado público, cujo alcance e especificidade decorrem das estratégias estabelecidas pelo PNI, hoje responde por aproximadamente $90 \%$ da demanda por doses de vacinas humanas no país 38 . Esse programa tem se revelado cada vez mais inserido numa realidade de futuro, mediante a contínua inserção de novas tecnologias e produtos de última geração ${ }^{39}$. A capacidade brasileira de organizar e promover campanhas nacionais de vacinação - atreladas a um calendário anual que atualmente abrange no mínimo 18 enfermidades, atinge todas as faixas etárias e envolve grandes segmentos populacionais - é reconhecida como um exemplo mundial 40,41. A amplitude do PNI associada ao tamanho da população brasileira qualificam o Brasil como um dos maiores mercados mundiais em termos de volume de doses de vacinas.

Já o mercado privado emergiu voltado para proporcionar o acesso diferenciado a vacinas modernas ainda não fornecidas pela rede pública de saúde - oportunizado pelo descompasso tecnológico entre a oferta de produtos pelo PNI e o ritmo do desenvolvimento de novas vacinas no início dos anos 1980 -, que produziu um espaço de desigualdade até então inexistente no país 7,37, mas que acabou funcionando como uma porta de entrada de vacinas tecnologicamente mais avançadas no mercado público nacional.

Do lado da oferta, dados do PNI e da CMED sobre o ano de 2017 revelam que esse mercado nacional foi atendido por um número limitado de fornecedores: quatro instituições públicas - Instituto de Tecnologia em Imunobiológicos (Bio-Manguinhos/Fiocruz), Fundação Ataulpho de Paiva (FAP), Instituto Butantan e Fundação Ezequiel Dias (Funed) -, por cinco grandes empresas integrantes dos principais conglomerados internacionais do setor - Abbott, GSK, Merck, Pfizer e Sanofi - 13,14, e por dois organismos internacionais - OPAS e a Organização das Nações Unidas para a Educação, a Ciência e a Cultura (UNESCO), cujos fornecimentos incluem vacinas produzidas por empresas que não correspondem aos conglomerados citados, como o Serum Institute of India 13,14.

A despeito do tamanho da demanda brasileira e da atuação dos grandes conglomerados farmacêuticos no fornecimento de vacinas no país, a última empresa privada fabricante no Brasil encerrou suas atividades ainda nos anos 1980 37. Atualmente, toda a produção nacional é realizada por produtores públicos que, incentivados pelo Programa Nacional de Autossuficiência em Imunobiológicos (PASNI), utilizaram estratégias de transferência de tecnologia para a ampliação de seus portfólios e capacitação na produção de vacinas demandadas pelo PNI, em especial aquelas da fronteira tecnoló- 
gica. GSK, Merck e Sanofi Pasteur foram os principais fornecedores das tecnologias transferidas aos laboratórios públicos brasileiros nos últimos anos, como demonstra o Quadro 1.

Essas empresas, além de figurarem como as principais produtoras mundiais de vacinas humanas contra doenças infecciosas, são as protagonistas globais nas atividades de P\&D do segmento e as detentoras do maior volume dos ativos patentários no mundo e também no Brasil, como revelou a pesquisa realizada na base de dados Questel Orbit Intelligence (https://www.questel.com/businessintelligence-software/orbit-intelligence/\#, acessado em 23/Jun/2019).

O estudo realizado identificou um universo de 1.475 famílias de patentes na área de vacinas humanas - tanto profiláticas quanto terapêuticas - vigentes no território brasileiro. Reunidas todas as empresas pertencentes a um mesmo grupo econômico, foi observado que a britânica GSK é a líder de depósitos no país, seguida pelas empresas Oncotherapy Science (japonesa), Immatics Biotechnologies (alemã), Merck (americana), Sanofi (francesa) e Pfizer (americana). A participação de empresas nacionais nesse ranking é irrisória. A expressiva participação da GSK no Brasil, como pode ser visto na Figura 2, reflete no país o seu protagonismo mundial no depósito de patentes nesse segmento de mercado.

Na área pública, o principal titular de famílias de patentes no Brasil é o U.S. Department of Health and Human Services (HHS), na nona posição, como se observa na Figura 2. A Fiocruz é a brasileira que primeiro desponta dentre as nacionais, aparecendo no 35o lugar, com seis famílias de patentes.

Uma análise detalhada do escopo dos portfólios de famílias de patentes no Brasil revela diferentes cenários. A principal depositante no país, a GSK, possui rol de invenções diversificado na área de vacinas. A maior concentração é de famílias de vacinas contra meningites (meningocócica e pneumocócica) (16), seguida de câncer (14), tríplice bacteriana, contra difteria, tétano e pertússis (DTP) (12), pneumonia (11), alergias (10), malária e HIV (9 famílias cada). Com menor número de famílias, mas com presença significativa, encontram-se depósitos na área de influenza (8), do vírus sincicial respiratório (RSV) e vacinas para aumento da imunidade (6 famílias cada). As demais famílias estão pulverizadas entre Clostridium difficile, clamídia, rotavírus, vetores poxvirus, arteriosclerose, Alzheimer, dentre outras.

\section{Quadro 1}

Transferência de tecnologia para laboratórios públicos no Brasil.

\begin{tabular}{|l|c|c|}
\hline PRODUTOR PÚBLICO & VACINA & FORNECEDOR DA TECNOLOGIA \\
\hline \multirow{4}{*}{ Fiocruz } & HIB (Haemophilus influenzae do sorotipo B) & SmithKline/GSK * \\
\cline { 2 - 3 } & Pneumocócica 10-valente (conjugada) & GSK \\
\cline { 2 - 3 } & Rotavírus (atenuada) & GSK \\
\cline { 2 - 3 } & Tríplice viral (sarampo, caxumba e rubéola) \\
\cline { 2 - 3 } & Tetra viral (sarampo, caxumba, rubéola e varicela) & GSK \\
\cline { 2 - 3 } & VIP (poliomielite inativada) & Sanofi Pasteur \\
\hline Funed & Meningocócica C & Novartis/GSK \\
\hline Instituto Butantan & HPV (papilomavírus humano) & Merck \\
\cline { 2 - 3 } & Hepatite A & Merck \\
\cline { 2 - 3 } & Pertússis acelular & GSK \\
\cline { 2 - 3 } & Influenza & Sanofi Pasteur \\
\hline
\end{tabular}

Fiocruz: Fundação Oswaldo Cruz; Funed: Fundação Ezequiel Dias.

* O contrato de transferência de tecnologia da vacina HIB foi assinado originalmente em 1998 com a empresa Smithkline Beecham (SmithKline). Nos anos 2000, com a fusão da Glaxo Wellcome com a Smithkline Beecham, a transferência de tecnologia em curso passou a ser conduzida pelo grupo GlaxoSmithKline (GSK).

Fonte: elaborado pelos autores a partir de dados do Relatório de Atividades do Instituto de Tecnologia em Imunobiológicos (Bio-Manguinhos/ Fiocruz)/2017, Relatório de Gestão da Fundação Butantan/2018 e Funed/2019. 
Figura 2

Líderes no depósito de famílias de patentes (ativas) na área de vacinas humanas no território brasileiro (1999-2017 *).

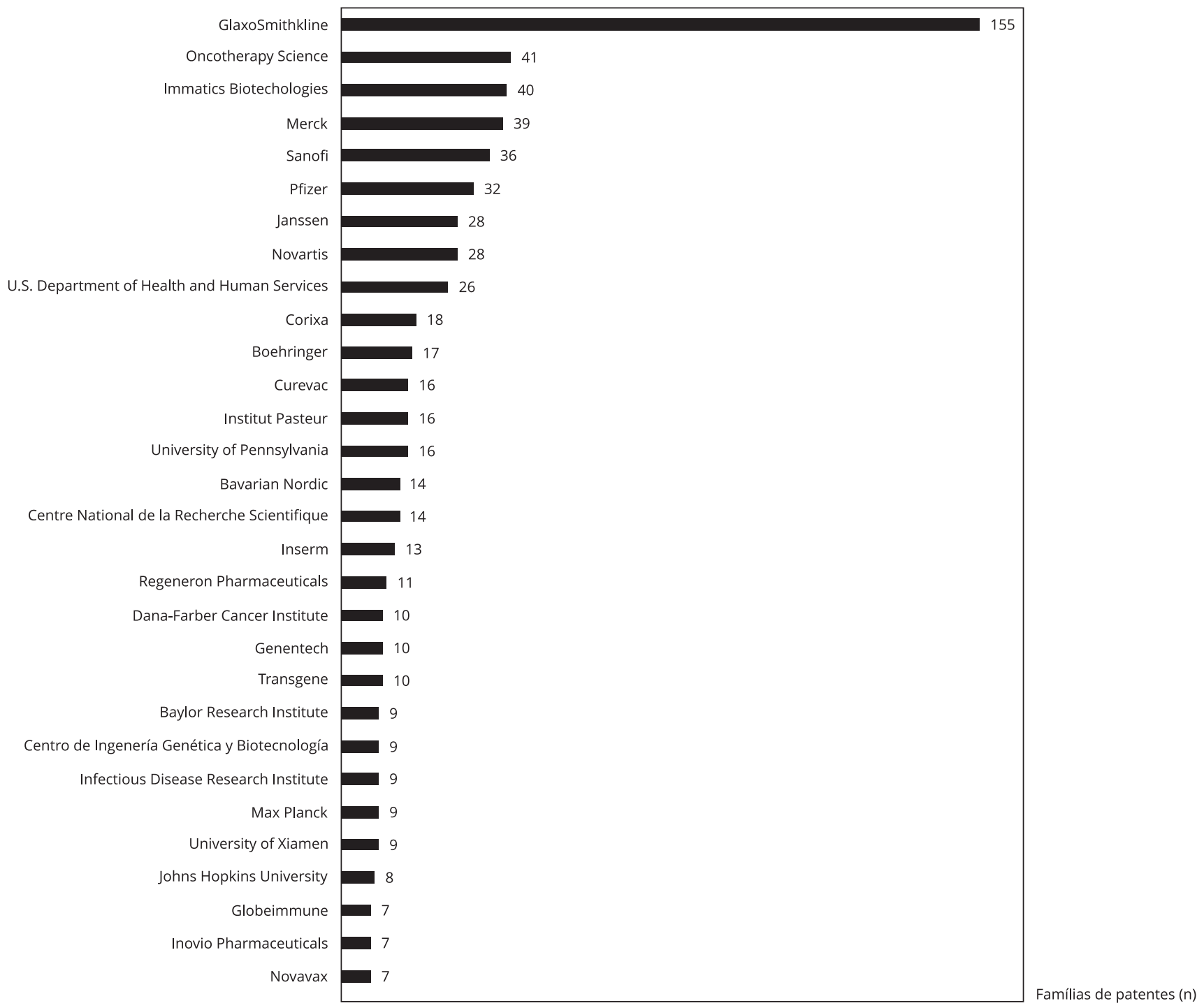

* 2017 é o último ano cujos depósitos de patente estão informados publicamente. A maior parte dos depósitos de patente entre 2018 e 2019 estão em sigilo, devido à regra de 18 meses entre o depósito de um pedido e a sua publicação nas revistas de propriedade industrial.

Fonte: informações geradas no Questel IP Business Intelligence (https://www.questel.com/business-intelligence-software/orbit-intelligence/\#), a partir de busca realizada pelos autores, acesso entre junho e julho/2019.

Tal portfólio, em parte, apresenta correspondência com a atuação histórica da empresa como fornecedora de vacinas e de tecnologia para os laboratórios públicos no Brasil. Muitos depósitos de patente fazem parte da nova geração das vacinas já fornecidas, outras são novos desenvolvimentos. Com relação às patentes depositadas para alvos inéditos ou pouco explorados, como as arboviroses e doenças parasitárias, a GSK possui depósitos somente para vacina contra dengue e malária. É importante notar também o grande investimento em vacinas terapêuticas para câncer, as 14 famílias do portfólio abrangem diversos tipos da doença. 
Foi verificada forte tendência de investimentos na área de câncer. Além da presença relevante dentre as famílias de patentes da GSK, as duas empresas próximas colocadas no ranking brasileiro apresentam portfólios extremamente concentrados nesse segmento. A empresa Oncotherapy Science mantém 39 famílias de patentes, em diversos tipos da doença, e apenas duas famílias de patentes para a área ótica (maculopatia). Já a Immatics Biotechnologies possui portfólio cem por cento voltado para diversos tipos de câncer.

Com portfólio mais diversificado, a Merck possui nove famílias na área de terapias contra câncer. As demais apostas dessa empresa são, em ordem de quantidade de famílias: dengue, meningite meningocócica, alergia, HIV, doenças causadas por flavivírus, Alzheimer, rotavírus, além de outras áreas, com apenas uma família depositada (RSV, pneumonia, varicela, citomegalovírus e C. difficile).

Já a Sanofi possui portfólio semelhante ao da GSK quanto às escolhas dos alvos. São nove famílias relacionadas a meningites (meningocócica e pneumocócica), duas para hepatite B, duas para doenças pneumocócicas e duas correspondentes à vacina DTP. A característica mais peculiar é o investimento em arboviroses causadas por flavivírus: cinco famílias contra dengue, uma contra febre do Nilo e outras três sem doença alvo específica.

Fazendo paralelo entre o instituto americano HHS (a primeira instituição pública no ranking) e a Fiocruz (o primeiro instituto público brasileiro do ranking), observa-se grande semelhança no que se refere às arboviroses: a Fiocruz possui famílias para doenças causadas por flavivírus, na maioria contra febre amarela, enquanto o HHS possui famílias para zika e dengue. Diferem, entretanto, nos demais tipos de proteção: a Fiocruz possui famílias de patentes contra malária e helmintos, enquanto as demais famílias do HHS estão nas áreas de câncer, RSV, filovírus, influenza, pneumonia, papiloma, tuberculose, leishmaniose, rotavírus, dentre outras.

Considerando o mercado de vacinas humanas contra doenças infecciosas no Brasil, GSK, Merck e Sanofi figuram como as principais titulares de famílias de patentes, o que lhes garante reserva do mercado público nacional independente do fato de não investirem em P\&D ou produzirem vacinas no país.

\section{O mercado brasileiro de vacinas: análise de dados do PNI e balança comercial}

A investigação realizada em dados primários do PNI, referentes ao decênio 2009-2018, revelou que a Fiocruz e o Instituto Butantan são os principais fornecedores do PNI, tanto em variedade de vacinas quanto em volume de doses, e que os fornecedores privados atendem a demanda residual não suprida pelos laboratórios públicos. O Quadro 2 apresenta os fornecimentos realizados em 2018 ao PNI, por laboratório público e por modalidade de vacina; já a Figura 3 consolida o histórico global dos fornecimentos ao PNI, por volume de doses no período.

Além disso, o que se observou foi que o dispêndio público do PNI na aquisição de vacinas sofreu um significativo aumento no período, como revela a Figura 4. Essa majoração, entretanto, não se deve ao aumento no número de doses de vacinas adquirido por ano, mas ao custo médio da dose, mesmo considerado o valor em dólares - em 2009, USD 1,43; em 2018, USD 4,07 - o que coincide com o aumento do custo internacional das vacinas de última geração, então associado à crescente complexidade tecnológica do segmento e à concentração manifesta nesse mercado. Se considerado apenas o ano de 2018, o que se verifica é que foram mais de 304 milhões de doses fornecidas para o PNI, a um custo total de mais de BRL 4,5 bilhões (USD 1,2 bilhão), como mostra a Figura 4.

Consideradas as aquisições realizadas pelo PNI em 2018, o que se verifica é a existência de uma grande variação de preço da dose da vacina: a mais barata foi a DTP que, produzida pelo Serum Institute of India, foi fornecida por BRL 0,69; enquanto a mais cara, contra a varicela, produzida pela Merck Sharp \& Dohme, foi fornecida a BRL 75,20.

Realizando um comparativo entre o número de doses e o preço da dose das diversas vacinas adquiridas, o que se observa é que a influenza é a vacina mais crítica, não pelo custo da dose, mas pelo grande volume adquirido, o que pode ser observado na Figura 5.

A Figura 5 adicionalmente revela que as vacinas contra HPV, meningite meningocócica C conjugada, pneumocócica 10 e varicela também são críticas em termos de preço. Expõe, ademais, que a tensão global entre valor de mercado, atendimento às demandas sociais e preços, inerentes à dinâmica do CEIS 42, pode se reproduzir no campo das vacinas. Essa tensão impõe a necessidade de uma estra- 
Quadro 2

Laboratórios públicos - fornecimentos ao Programa Nacional de Imunização (PNI). Vacinas humanas (2018).

\begin{tabular}{|c|c|}
\hline LABORATÓRIO * & VACINA \\
\hline \multirow[t]{8}{*}{ Fiocruz ** } & Febre amarela \\
\hline & HIB (Haemophilus influenzae do sorotipo B) \\
\hline & VIP (poliomielite inativada) \\
\hline & VOP (poliomielite oral) \\
\hline & Pneumocócica 10 valente \\
\hline & Tríplice viral (caxumba, sarampo e rubéola) *** \\
\hline & Tetra viral (caxumba, sarampo, rubéola e varicela) \\
\hline & Rotavírus \\
\hline \multirow[t]{6}{*}{ Instituto Butantan } & Influenza \\
\hline & Hepatite A\# \\
\hline & Hepatite B \\
\hline & HPV (papilomavírus humano) \\
\hline & Raiva humana \\
\hline & dTpa (difteria, tétano e pertússis - acelular) \\
\hline FAP & BCG (tuberculose) \\
\hline Funed & Meningocócica C conjugada \\
\hline
\end{tabular}

FAP: Fundação Ataulpho de Paiva; Fiocruz: Fundação Oswaldo Cruz; Funed: Fundação Ezequiel Dias.

* Não foi incluído o Instituto de Tecnologia do Paraná (Tecpar), por ser fornecedor apenas de vacina veterinária para o PNI;

** Com base no relatório de gestão da Fiocruz, exercício de 2018, além das vacinas listadas acima, é apontado que a Fiocruz também forneceu a vacina contra a varicela;

*** No caso da vacina do tríplice viral, o PNI ainda foi abastecido por vacinas fornecidas pela Serum Institute of India e Merck Sharp \& Dohme;

\# No caso da vacina contra hepatite A, o PNI ainda foi parcialmente abastecido por vacinas fornecidas pela Merck Sharp \& Dohme.

Fonte: elaborado pelos autores com base nas informações do PNI/Departamento de Vigilância das Doenças Transmissíveis/Secretaria de Vigilância em Saúde/Ministério da Saúde.

tégia pública que permita a articulação do binômio inovação-acesso, reproduzindo uma dicotomia que, no limite, pode cindir a natureza de bem público das vacinas como segmento produtivo essencial para garantir o acesso universal.

Em um cenário de ampliação do portfólio do calendário de vacinação, com a incorporação de produtos ofertados pelo SUS, cuja tecnologia não estava ou ainda não está totalmente disponível no país, o que se verificou foi o progressivo aumento do déficit na balança comercial do setor, que começou a apresentar crescimento a partir de 1999. Em 2010, esse déficit registrou um crescimento de $308 \%$ - uma consequência da aquisição de um único produto, a vacina contra H1N1 -, que passou de pouco mais de USD 300 milhões em 2009 para mais de USD 1,2 bilhão. Apesar do recuo ocorrido na sequência, esse déficit não volta ao patamar anterior. Uma nova inflexão é verificada em 2014, quando o déficit ultrapassou os USD 930 milhões, voltando em seguida ao nível anterior, correspondendo a uma média de USD 664 milhões nos anos de 2015 a 2018.

Observado o papel do segmento de vacinas para a conformação do déficit da balança comercial do CEIS, o que se observa é que a participação vem gradativamente crescendo. Hoje já é responsável por $6 \%$ do déficit total do CEIS e $9 \%$ do déficit quando se considera apenas o segmento de base química e biotecnológica (Figura 6). 


\section{Figura 3}

Aquisições de vacinas pelo Ministério da Saúde: número de doses 2009-2018.

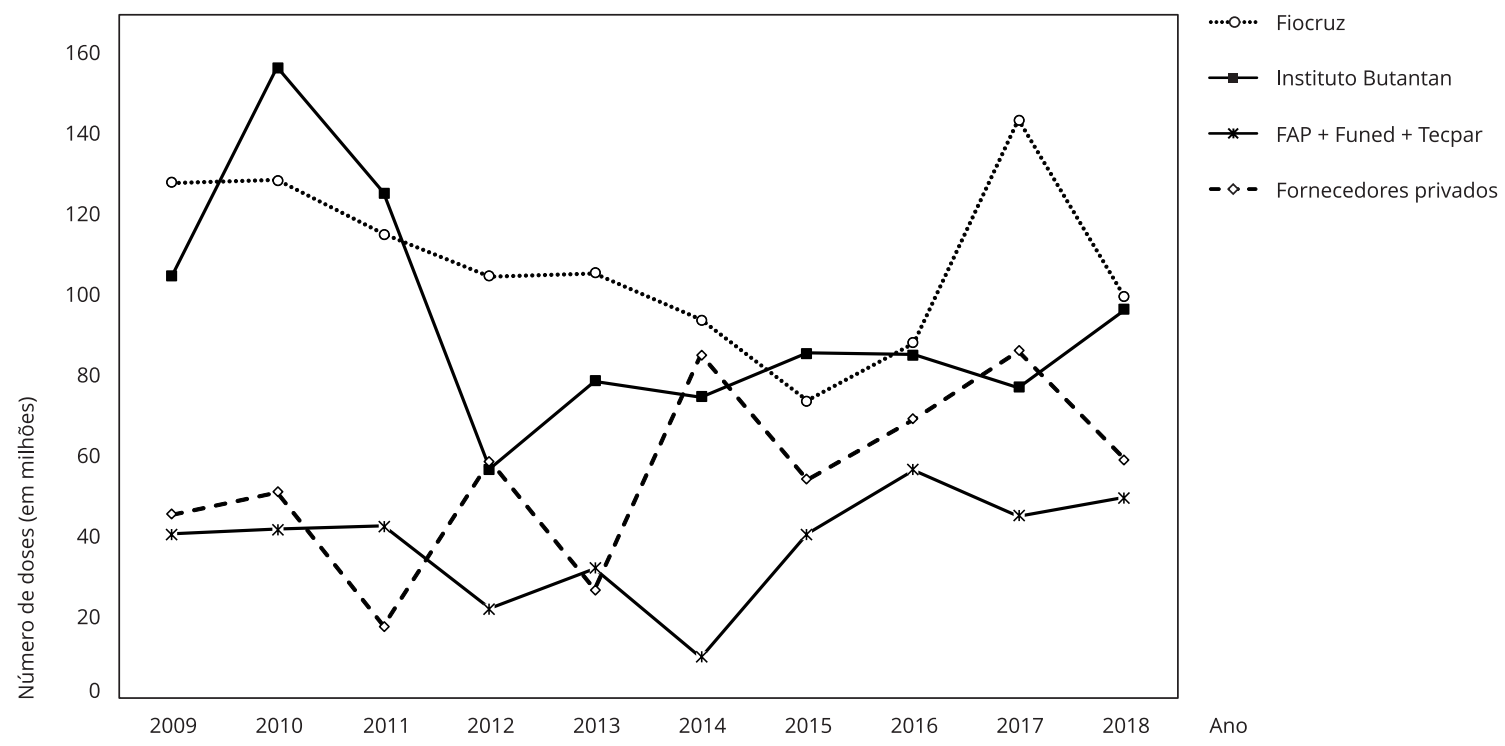

FAP: Fundação Ataulpho de Paiva; Fiocruz: Fundação Oswaldo Cruz; Funed: Fundação Ezequiel Dias; Tecpar: Instituto de Tecnologia do Paraná. Fonte: elaborado pelos autores com base nas informações do Programa Nacional de Imunizações/Departamento de Vigilância das Doenças Transmissíveis/Secretaria de Vigilância em Saúde/Ministério da Saúde.

\section{Figura 4}

Programa Nacional de Imunizações (PNI). Aquisição de vacinas - principais fornecedores (milhões de doses) (2009-2018).

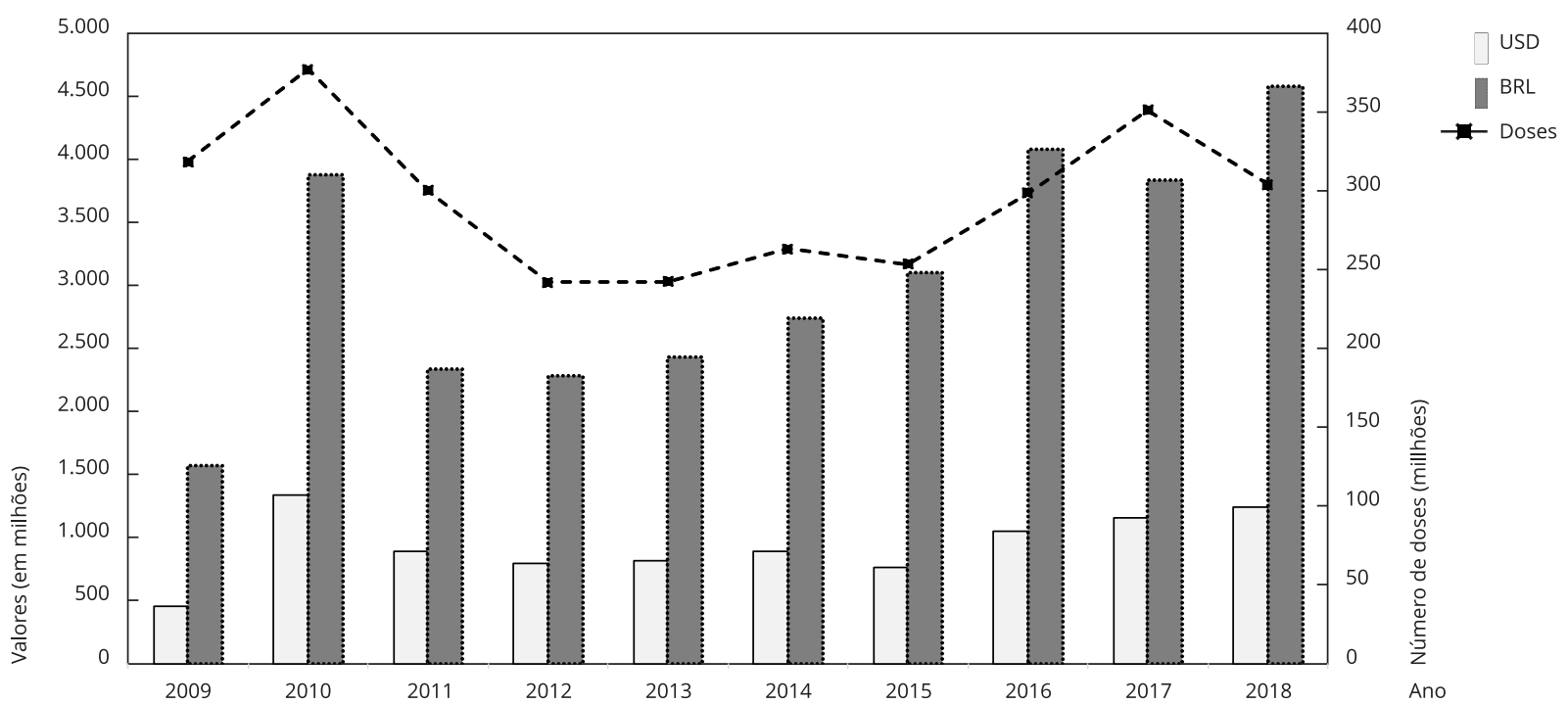

Fonte: elaborado pelos autores com base nas informações do PNI/Departamento de Vigilância das Doenças Transmissíveis/Secretaria de Vigilância em Saúde/Ministério da Saúde. 
Figura 5

Aquisições do Programa Nacional de Imunizações (PNI) (2018) - doses adquiridas x dispêndio total x preço médio por dose *.

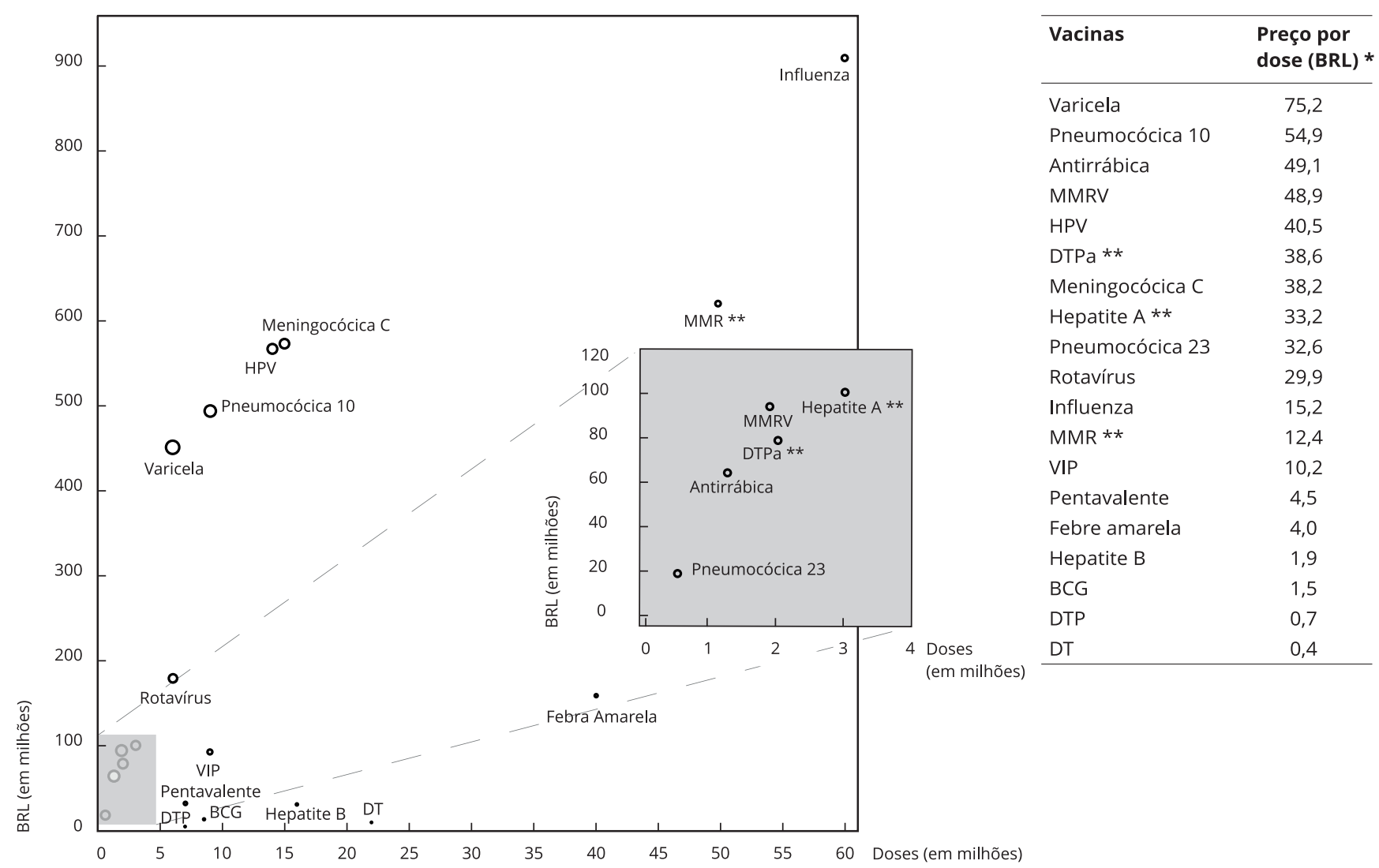

Abreviaturas e indicação: BCG (bacilo de Calmette \& Guérin, contra tuberculose); DT (contra difteria e tétano); DTP (contra difteria, tétano e pertússis); DTPa (contra difteria, tétano e pertússis, acelular); HPV (contra infecção causada pelo papilomavírus humano); Influenza (contra a gripe); MMR (em inglês measles, mumps, and rubella, contra caxumba, sarampo e rubéola); MMRV (em inglês measles, mumps, rubella and varicella, contra caxumba, sarampo, rubéola e varicela); Pentavalente (contra difteria e tétano, pertússis, hepatite B e Haemophilus influenzae tipo B); VIP (vacina inativada contra poliomielite).

* Havendo mais de um fornecedor para a mesma vacina, foi calculado o preço médio final pago por dose;

** O preço da dose da vacina MMR foi o que apresentou a maior variação. Provenientes de quatro fornecedores distintos, foi de BRL 6,40 a BRL 24,55 (valor médio, BRL 12,40). Variação significativa também foi verificada na dose da vacina contra hepatite A (a mais barata a BRL 33,00 e a mais cara a BRL 50,68) e da DTPa (a mais barata a BRL 38,14 e a mais cara a BRL 59,60). No caso das vacinas contra hepatite A e DTPa, a aquisição de doses mais caras foi pequena e não impactou significativamente o preço médio final.

Nota: o tamanho do círculo indica o preço por dose (BRL 0,40 a BRL 75,20). As marcas são rotuladas por seu nome abreviado. A figura à esquerda amplia a visão sobre a área da figura com vendas inferiores a BRL 120 milhões e doses aplicadas inferiores a 3,5 milhões.

Fonte: elaborado pelos autores com base nas informações do PNI/Departamento de Vigilância das Doenças Transmissíveis/Secretaria de Vigilância em Saúde/Ministério da Saúde. 
Figura 6

Participação no déficit, por segmento (no Complexo Econômico-Industrial da Saúde - CEIS e no setor farmacêutico).

6a) Participação por segmento no déficit do CEIS

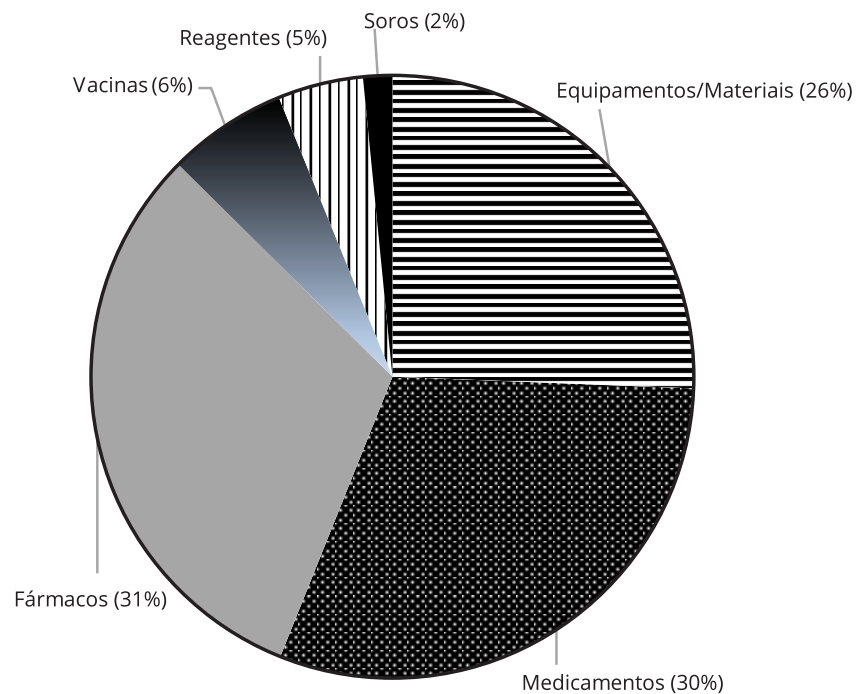

6b) Participação por segmento no déficit do setor farmacêutico

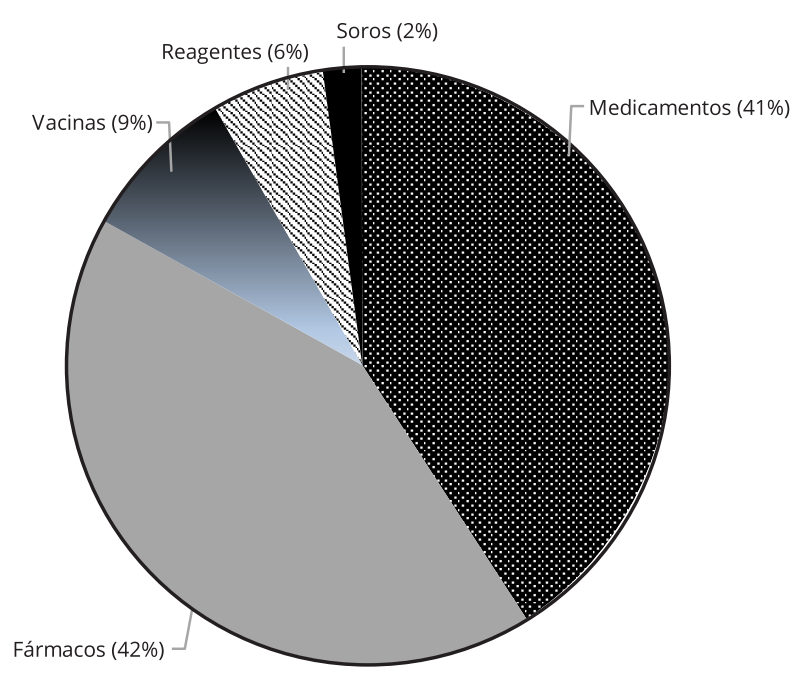

Fonte: elaborado pelos autores com base em metodologia desenvolvida pela Coordenação das Ações de Prospecção da Presidência/Grupo de Pesquisa sobre Desenvolvimento, Complexo Econômico-Industrial e Inovação em Saúde/Fundação Oswaldo Cruz, a partir de dados do Comex Stat do Ministério da Indústria, Comércio Exterior e Serviços (http://comexstat.mdic.gov.br/pt/geral, acessado em Fev/2019).

Esses dados evidenciam a fragilidade tecnológica nacional e a inserção do país no quadro de assimetrias globais associadas à difusão não equânime do progresso técnico e das inovações em saúde. Em termos das políticas públicas e quanto ao papel dos laboratórios públicos, essa situação revela a necessidade premente de associar os processos de transferência de tecnologia com estratégias de capacitação endógena, sob pena de uma reprodução permanente e estrutural das condições de dependência mesmo no segmento do CEIS em que foi possível avançar mais no Brasil.

\section{Conclusões}

Nos últimos cinco anos, o ritmo de inovação no segmento de vacinas arrefeceu 26,28 , mas não se refletiu na importância econômica desse segmento no CEIS 30,31,32,43. Uma análise estática pode induzir à conclusão de que as vacinas estão retrocedendo frente a outros grupos de produtos. Na realidade, a promessa das vacinas como porta de entrada nas modernas biotecnologias foi cumprida. No entanto, a subordinação desse segmento à estratégia das empresas líderes farmacêuticas se acentuou, reforçando assimetrias globais e barreiras de acesso 27,28, o que pode ampliar o distanciamento entre inovações e as demandas sanitárias de populações e regiões negligenciadas.

Esse cenário se reproduz no Brasil. O cruzamento de dados de mercado, mediante pesquisa em documentos oficiais dos laboratórios públicos nacionais e investigação sobre o panorama da proteção patentária no país, revela que as grandes líderes globais do segmento também orientam o padrão tecnológico dominante no mercado brasileiro. A produção nacional é exclusivamente pública e subordinada, essencialmente, a estratégias de transferência de tecnologia. Essas iniciativas, entretanto, não têm sido suficientes para reverter as condições de dependência estrutural e de longo prazo, como revelam os dados econômicos, de P\&D e da balança comercial. A incipiente, quase inexistente, 
participação de instituições e empresas nacionais no depósito de patentes no Instituto Nacional da Propriedade Industrial (INPI) para a proteção de tecnologias inerentes ao desenvolvimento e produção de vacinas aponta para a tendência de manutenção e mesmo ampliação do domínio do padrão tecnológico das grandes líderes globais no país.

O Brasil teve êxito em instalar uma base produtiva que tem sido importante para garantir o acesso universal à vacinação no país, mas os esforços de inovação ainda têm se mostrado insuficientes. $\mathrm{O}$ principal desafio é justamente ir além das estratégias que vinculam base produtiva local e demanda pública nacional para alcançar a capacitação para inovar. Essa perspectiva contribui para a superação do dilema global de direcionamento dos esforços de ciência, tecnologia e inovação em saúde para as necessidades sociais em bases sustentáveis e menos assimétricas, permitindo uma maior variedade de atores, países e alternativas tecnológicas.

\section{Colaboradores}

C. A. G. Gadelha foi responsável pela coordenação do estudo, concepção, definição do enfoque metodológico, discussão, redação, análise crítica do conteúdo, revisão e aprovação final da versão publicada. P. S. C. Braga foi responsável pela estruturação da redação do artigo; participou da coordenação do estudo, da análise crítica do conteúdo e revisão do artigo; colaborou com a revisão bibliográfica, levantamento e sistematização de dados. K. B. M. Montenegro foi responsável pelo levantamento e sistematização de dados; participou da redação, da análise crítica do conteúdo e da revisão do artigo. B. B. Cesário participou do levantamento e sistematização de dados, da redação e análise crítica do conteúdo do estudo.

\section{Informações adicionais}

ORCID: Carlos Augusto Grabois Gadelha (00000002-9148-8819); Patricia Seixas da Costa Braga (0000-0002-3444-1651); Karla Bernardo Mattoso Montenegro (0000-0003-1773-7781); Bernardo Bahia Cesário (0000-0002-2241-9860).

\section{Agradecimentos}

Os autores agradecem a Marco Nascimento, Leandro Safatle e Felipe Kamia (Coordenação das Ações de Prospecção e Grupo de Pesquisa sobre Desenvolvimento, Complexo Econômico-Industrial e Inovação em Saúde/Fiocruz), pelas sugestões sobre a análise e os levantamentos efetuados. Também à Leila Longa (Coordenação de Gestão Tecnológica/ Fiocruz), à Fabrícia Pimenta (Centro de Desenvolvimento Tecnológico em Saúde/Fiocruz), e aos profissionais do PNI/Ministério da Saúde pelas suas valorosas contribuições no levantamento de informações em suas respectivas áreas de atuação. Este artigo contou com suporte financeiro do Conselho Nacional de Desenvolvimento Científico e Tecnológico $(\mathrm{CNPq})$, bolsa de produtividade de pesquisa de C. A. G. Gadelha.

\section{Referências}

1. Anderson RM. The impact of vaccination on the epidemiology of infectious diseases. In: Bloom BR, Lambert P-H, editors. The vaccine book. 2nd Ed. London: Elsevier; 2016. p. 3-31.

2. Bloom BR, Lambert P-H. Preface. In: Bloom BR, Lambert P-H, editors. The vaccine book. 2nd Ed. London: Elsevier; 2016. p. xv-xxvii.

3. World Health Organization. Global vaccine action plan 2011-2020. https://www.who.int/ immunization/global_vaccine_action_plan/ GVAP_doc_2011_2020/en/ (acessado em 19/ $\mathrm{Fev} / 2019$ ).

4. Gadelha CAG. O complexo industrial da saúde e a necessidade de um enfoque dinâmico na economia da saúde. Ciênc Saúde Colet 2003; 8:521-35.

5. Temporão JG, Gadelha CAG. The Health Economic-Industrial Complex (HEIC) and a new public health perspective. Oxford Research Encyclopedias Glob Public Health. https:// oxfordre.com/publichealth/view/10.1093/ acrefore/9780190632366.001.0001/acrefore9780190632366-e-27 (acessado em 29/Jul/ 2019).

6. Gadelha CAG, Temporão JG. A indústria de vacinas no Brasil: desafios e perspectivas. Estudo setorial. Rio de Janeiro: Banco Nacional de Desenvolvimento Econômico e Social; 1999.

7. Temporão JG. A indústria de vacinas e as estratégias de comercialização. Saúde Debate 2003; 27:101-9.

8. Schumpeter J. Capitalismo, socialismo e democracia. Rio de Janeiro: Fundo de Cultura; 1961.

9. Schumpeter JA. Theory of economic development. 3rd Ed. Cambridge: Harvard University Press; 1949.

10. Dosi G, Freeman C, Nelson R, Soete L, editors. Technical change and economic theory. London: Pinter Publishers; 1988.

11. Nelson RR, Winter SG. An evolutionary theory of economic change. Cambridge: Belknap Press; 1982. 
12. Agência Nacional de Vigilância Sanitária. Anuário estatístico do mercado farmacêutico 2017. http://portal.anvisa.gov.br/do cuments/374947/3413536/Anu\%C3\%A 1 rio+Estat\%C3\%ADstico+do+Mercado+Far mac\%C3\%AAutico+-+2017/3179a522-1af 4-4b4c-8014-cc25a90fb5a7 (acessado em 13/ Mar/2019).

13. Câmara de Regulação do Mercado de Medicamentos. Listas de preços de medicamentos. http://portal.anvisa.gov.br/listas-de-precos (acessado em 10/Abr/2019).

14. Câmara de Regulação do Mercado de Medicamentos. Lista de preços máximos para compras públicas. http://portal.anvisa.gov.br/lis tas-de-precos/compras-publicas (acessado em 10/Abr/2019).

15. Cassiolato JE, Stallivieri F, Rapini M, Podcameni MGB. Indicadores de inovação: uma análise crítica para os BRICS. Rio de Janeiro: RedeSist, Instituto de Economia, Universidade Federal do Rio de Janeiro/Aalborg: Globelics/ Department of Business Studies, Aalborg University; 2008.

16. Furtado C. Teoria e política do desenvolvimento econômico. 2a Ed. São Paulo: Nova Cultural; 1986.

17. Hausmann R. The atlas of economic complexity: mapping paths to prosperity. Cambridge: Center for International Development, Harvard University; 2011.

18. Gadelha CAG, Nascimento MAC, Braga PSC, Cesário BB. Transformações e assimetrias tecnológicas globais: estratégia de desenvolvimento e desafios estruturais para o Sistema Único de Saúde. Ciênc Saúde Colet 2018; 23:2119-32.

19. Valentim RAM, Coutinho KD, Morais AHF, Lima TS, Guimarães MCS, Silva Neto JHV. Conectividade e digitalização no contexto da saúde global: um olhar para o futuro inspirado na saúde 4.0. In: Departamento do Complexo Industrial e Inovação em Saúde, Secretaria de Ciência, Tecnologia e Insumos Estratégicos, Ministério da Saúde, organizador. Avanços, desafios e oportunidades no Complexo Industrial da Saúde em serviços tecnológicos. Brasília: Ministério da Saúde; 2018. p. 254-73.

20. Griesenauer RH, Kinch MS. An overview of FDA-approved vaccines \& their innovators. Expert Rev Vaccines 2017; 16:1253-66.

21. Mazzucato M. The entrepreneurial state: debunking public vs. private sector myths. London: Anthem Press; 2013.

22. Bahia L, Scheffer M, Tavares LR, Braga IF. From health plan companies to international insurance companies: changes in the accumulation regime and repercussions on the healthcare system in Brazil. Cad Saúde Pública 2016; 32 Suppl 2:e00154015.

23. Hiratuka C, Rocha MA, Sarti F. Mudanças recentes no setor privado de serviços de saúde no Brasil: internacionalização e financeirização. In: Gadelha P, Noronha JC, Daim S, Pereira TR, organizadores. Brasil saúde amanhã: população, economia e gestão. Rio de Janeiro: Editora Fiocruz; 2016. p. 189-220.
24. Keja K, Chan C, Hayden G, Henderson RH. Expanded programme on immunization. World Health Stat Q 1988; 41:59-63.

25. Landim AB, Pimentel VP, Gomes RP, Pieroni JP. Tendências internacionais e oportunidades para o desenvolvimento de competências tecnológicas na indústria brasileira de vacinas. BNDES Setorial 2012; (35):189-232.

26. Azimi T, Conway M, Heller J, Sabow A, Tolub G. Refueling the innovation engine in vaccines. https://www.mckinsey.com/industries/ pharmaceuticals-and-medical-products/ourinsights/refueling-the-innovation-engine-invaccines\# (acessado em 15/Maio/2019).

27. Douglas RG, Samant VB. The vaccine industry. In: Plotkin SA, Orenstein WA, Offit PA, Edwards KM, editors. Plotkin's vaccines. 7th Ed. Philadelphia: Elsevier; 2018. p. 41-50.

28. DeFrancesco L. Drug pipeline: 1Q18. Nature Biotechnol 2018; 36:386.

29. Gadelha CAG. Desenvolvimento e saúde: em busca de uma nova utopia. Saúde Debate 2007; 29:326-7.

30. Evaluate Pharma. World Preview 2019, outlook to 2024. http://info.evaluategroup.com/ rs/607-YGS-364/images/EvaluatePharma_ World_Preview_2019.pdf (acessado em 27/ Fev/2019).

31. Evaluate Pharma. World Preview 2018, outlook to 2024. http://info.evaluategroup.com/ rs/607-YGS-364/images/WP2018.pdf (acessado em 27/Fev/2019).

32. The Insight Partners. Vaccines market to 2027 - global analysis and forecasts by technology; disease indication; route of administration; patient type and geography. https://www.theinsightpartners.com/pr/vaccines-market (acessado em 24/Mai/2019).

33. Lim SS, Murray CJL. Introduction-global burden of disease addressed by current vaccines and vaccines in the development pipeline. In: Bloom BR, Lambert P-H, editors. The vaccine book. 2nd Ed. London: Elsevier; 2016. p. xxixxlii.

34. World Health Organization. Immunization, vaccine and biologicals. Vaccine market: global vaccine demand. https://www.who.int/immu nization/programmes_systems/procurement/ market/global_demand/en/ (acessado em 19/ Fev/2019)

35. World Health Organization. Immunization, vaccines and biologicas. Vaccine market: global vaccine supply. https://www.who.int/im munization/programmes_systems/procure ment/market/global_supply/en/ (acessado em 19/Fev/2019).

36. World Health Organization. Global vaccine market report. http://origin.who.int/immuni zation/programmes_systems/procurement/ v3p/platform/module2/MI4A_Global_Vac cine_Market_Report.pdf (acessado em 19/ Fev/2019).

37. Temporão JG. O mercado privado de vacinas no Brasil: a mercantilização no espaço da prevenção. Cad Saúde Pública 2003; 19:1323-39. 
38. Guimarães R, Noronha J, Elias FTS, Gadelha CAG, Carvalheiro JR, Ribeiro A, et al. Política de ciência, tecnologia e inovação em saúde. Ciênc Saúde Colet 2019; 24:881-6.

39. Zorzetto R. As razões da queda na vacinação. Pesquisa FAPESP 2018; (270):19-24.

40. Ministério da Saúde. Programa Nacional de Imunizações: 40 anos. http://bvsms.saude. gov.br/bvs/publicacoes/programa_nacional_ imunizacoes_pni40.pdf (acessado em 15/Mar/ 2019).
41. Schatzmayr HG. Novas perspectivas em vacinas virais. Hist Ciênc Saúde-Manguinhos 2003; 10 Suppl 2:655-69.

42. Gadelha CAG, Braga PSC. Saúde e inovação: dinâmica econômica e Estado de Bem-Estar Social no Brasil. Cad Saúde Pública 2016; 32 Suppl 2:e00150115.

43. Ferreira CG, De Melo AC, Stefani S, Vianna D, Fernandes G, Gadelha CG. Increasing access to immuno-oncology therapies in Brazil. J Cancer Policy 2018; 16:1-5. 
Abstract

This study analyzed the main economic trends, market structure, production, and innovation in vaccines against infectious diseases at the global and national levels, observing the effects on access to vaccination in Brazil and on the sustainability of the Brazilian Unified National Health System. In order to update a global overview of Res $D$ and the market, the authors conducted a literature search and drew on a competitive intelligence database. In order to understand Brazil's role in this context, with the Health Economic-Industrial Complex as the structural focus, the authors accessed information from the Brazilian Health Regulatory Agency, the National Immunization Program, and the Questel Orbit Intelligence database on patent protection in Brazil; identified the technologies transferred to public institutions in Brazil; and analyzed the trend in the trade balance deficit in health. The analysis revealed a global trend of concentration of vaccine production in a few leading pharmaceutical companies and the exacerbation of economic and technological asymmetries in the vaccine sector. In Brazil, the study identified technological weaknesses, risks, and manufacturing bottlenecks that impact the guarantee of immunizations in the country and showed that despite the installed industrial base, public policies and actions by domestic manufacturers have not been sufficient to confront and overcome the global context of structural dependence. In conclusion, the study indicates the need for progress in the Brazilian national strategy to link domestic production, technological capacitybuilding, and innovation in the vaccine sector to help guarantee universal access to health in Brazil.

National Science, Technology and Innovation Policy; Vaccines; Immunization Programs; Innovation; Access to Essential Medicines and Health Technologies

\section{Resumen}

Este estudio investigó las principales tendencias económicas, de estructura de mercado, y de producción e innovación en vacunas contra enfermedades infecciosas, en el ámbito global y nacional, observando sus reflejos en el acceso a la vacunación en Brasil y sostenibilidad del Sistema Único de Salud. Para la actualización del panorama mundial de PresD y de mercado, se realizó una investigación bibliográfica y se utilizó una base de datos de inteligencia competitiva. Para la comprensión de la inserción de Brasil en ese contexto, según el enfoque estructural del Complejo Económico-Industrial de Salud, se recogió información de la Agencia Nacional de Vigilancia Sanitaria, del Programa Nacional de Inmunización y de la base Questel Orbit Intelligence, referente a la protección de patentes en el país; identificadas las tecnologías transferidas para las instituciones públicas nacionales; e investigada la evolución del déficit de la balanza comercial en salud. El análisis efectuado evidenció la tendencia global de concentración de la producción en pocas empresas farmacéuticas líderes y de exacerbación de asimetrías económicas y tecnológicas, también en el segmento de vacunas. En Brasil, la investigación identificó fragilidades tecnológicas, riesgos y cuellos de botella productivos que recaen sobre la garantía de inmunización en el país y reveló que, a pesar de la base industrial instalada, las políticas públicas y acciones de los productores nacionales no han sido suficientes para enfrentar y superar el contexto global de dependencia estructural. En conclusión, el estudio indica la necesidad de avanzar en la estrategia nacional de vincular la producción local, capacitación tecnológica y de innovación en el segmento de vacunas, para contribuir en la garantía del acceso universal a la salud en el país.

Política Nacional de Ciencia, Tecnología

e Innovación; Vacunas; Programas de

Inmunización; Innovación; Acceso a

Medicamentos Esenciales y Tecnologías Sanitarias
Recebido em 14/Ago/2019

Versão final reapresentada em 31/Jan/2020

Aprovado em 11/Fev/2020 